\title{
The Impact of Resistance Training on Gene Expression of IGF1 and Athletes' Physiological Parameters
}

\author{
Mohammed Nader Shalaby*(D), Mona Mostafa Abdo Sakoury ${ }^{2} \mathbb{D}$, Ellie Abdi $^{3} \mathbb{D}$, Shaimaa Elgamal ${ }^{4}$, Shaimaa \\ Elrkbwey ${ }^{4}$, Wael Ramadan ${ }^{5}$ D, Redha $\operatorname{Taiar}^{6}$ iD \\ ${ }^{1}$ Department of Biological Sciences and Sports Health, Faculty of Physical Education, Suez Canal University, Ismailia, \\ Egypt; ${ }^{2}$ Department of General Courses, Faculty of Applied Studies and Community Service, Imam Abd Al-Rahman Al Faisal \\ University, Dammam, Saudi Arabia; ${ }^{3}$ Center of Pedagogy, Montclair State University, Upper Montclair, New Jersey, USA; \\ ${ }^{4}$ Department of Health Sciences, Faculty of Physical Education for Girls, Alexandria University, Alexandria, Egypt; ${ }^{5}$ Department \\ of Sports Training, Faculty of Physical Education, Mansoura University, Mansoura, Egypt; ${ }^{6}$ Department of Physical and Sports \\ Education, Reims University, Reims, France
}

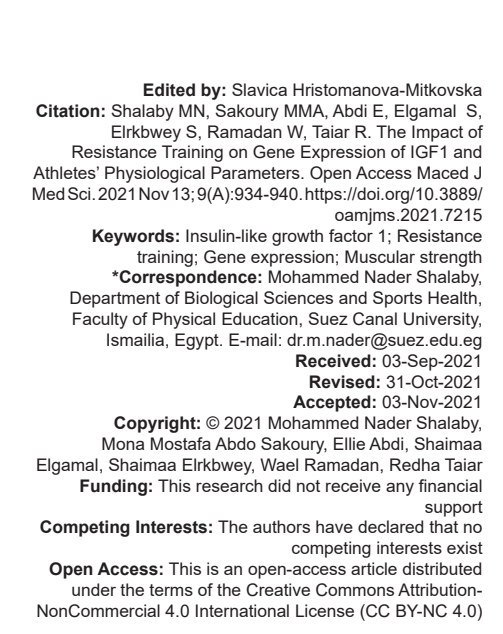

\section{Introduction}

Among the different modes of exercise, resistance training is known for its importance in enhancing the performance of athletes as it contributes to increasing speed, strength, power, and hypertrophy. This type of exercise is common among bodybuilders due to its efficacy in improving health and stimulating muscular tissue [1]. Moreover, resistance training can change the response of the endocrine system, stimulate protein synthesis, and consequently increase muscular mass in the long run. Among the most important anabolic hormones are insulin-like growth factor 1 (IGF1) and growth hormone (GH), both of which play a significant role in the mechanisms of anabolic adaptation to muscle tissue. It should be noted that there is a sort of interaction between them [2]. Strength exercises are well-known for their ability to evaluate physical fitness, their relevance for specific vocations, and the potential for athletic performance.

It is noteworthy that IGF1 is a 70 -amino acid peptide that has $70 \%$ homology with IGF11 and 50\% sequence homology with insulin [3]. IFG1 and IGF 1 are encoded by single large genes, the former being on the long arm of chromosome 12, whereas the latter is on the short arm of chromosome 11. Both IGFs, such as insulin, contains $A$ and $B$ chains linked by disulfide bonds. Their similar structure justifies the ability of IGF1 to bind to insulin receptors [1]. Barton-Davis et al. [4] suggest that IGF1 is constructed in the muscles and liver and has some anabolic effects. Moreover, IGF 1 leads to an increase in muscle bulk because its application is based on $\mathrm{GH}$ concentration. The researchers have noted that greater responses in muscle growth can be stimulated by combining Mechano-growth factor or IGF 1 with strength conditioning programs or other anabolic activities [4]. 
Furthermore, Ganguly [5] has shown that GH can stimulate the construction of some small proteins called somatomedin (IGF 1,2) by the liver and some other tissues. These proteins can increase all aspects of growth in a way similar to the influence of insulin on growth that is why they are called growth factors. Many researchers have demonstrated that Somatomedin C is responsible for most, if not all, growth influences made by $\mathrm{GH}$, whereas the direct impact of $\mathrm{GH}$ on muscle and tissues has not been attributed to this role. A sufficient amount of Somatomedin $\mathrm{C}$ can be released into the local tissue causing local growth due to the effect of $\mathrm{GH}$ which may be directly responsible for the increased growth. Thus, the somatomedin mechanism can be considered as another method to increase growth. About the mode action of IGF1, Humbel [6] has detected that IGF1 has a crucial contribution to the regulation of metabolism and growth in many cell types. However, IGF-IR is utilized to mediate the physiological effects of IGF1 [7]. In addition, it has been noticed that b- subunits of IGF-IR have an intracellular tyrosine kinase domain that is stimulated by ligand binding to $b$ - subunits and thus leads to phosphorylation of $b$ - subunits [8]. This kinase domain is necessary for the biological activity of IGF1 because the deficiency in intracellular kinase reception causes them to fail to mediate the effect of IGF1 [9].

Mougios [10] demonstrated that areas of gene expression and nucleic acids are considered the most paroxysmal in modern biochemistry. Although considered a relatively new area of study, it has gained more intense research activity. Mougios [10] also reported that nucleic acids consist of nucleotides. It is noteworthy that the building blocks of RNA are called ribonucleotides, whereas those in DNA are called deoxyribonucleotides. Nucleic acids are described here as the molecules that carry the hereditary pattern as they are responsible for storing and transmitting genetic information among generations. The labor is divided between DNA and RNA, the former is responsible for the process by which genetic information is stored, whereas the latter is responsible for the process by which this information is transmitted. The protein is synthesized according to the information carried by the gene; this process is called gene expression and is primarily performed at the level of transcription [11]. The purpose of this study to examine the effect of resistance training on changing gene expression for each player in a different way through the concentration of IGF1 as well as RNA expression. Some bodily modifications resulted in response to training and the anabolic hormone of IGF1.

\section{Materials and Methods}

\section{Participants}

The current study included 20 healthy players who are accustomed to training regularly. The participating volunteers were categorized into two groups: the control group and the experimental group. Height, weight, age, and study were determined (Table 1) and the participants' homogeneity concerning the previous aspects. The Ethics Committee of the University of Suez Canal approved the study, and consequently, the subjects were informed about the potential benefits of the life experiments research method, the objectives of the study, and potential discomfits before giving their written consent. The descriptive method was applied due to its suitability to the study.

Table 1: Basic characteristics and experimental and control groups in age, height, and weight

\begin{tabular}{lllllll}
\hline Variable & \multicolumn{2}{l}{ Experimental group } & & \multicolumn{2}{l}{ Control group } & Sig \\
\cline { 2 - 3 } & $\mathrm{M}$ & $\mathrm{SD}$ & & $\mathrm{M}$ & $\mathrm{SD}$ & \\
\hline Age $($ years $)$ & 20.4 & 2.7 & & 21.1 & 1.9 & NS \\
Height $(\mathrm{cm})$ & 175.3 & 4.2 & & 173.2 & 3.8 & NS \\
Weight $(\mathrm{kg})$ & 72.3 & 6.1 & & 71.7 & 5.3 & NS \\
BMI $\left(\mathrm{kg} / \mathrm{m}^{2}\right)$ & 21.3 & 2.1 & & 20.6 & 2.3 & NS \\
\hline BMI: Body mass index. & & & & &
\end{tabular}

\section{Experimental design}

An inclusion protocol was used, consisting of a physical examination of all participants. Researchers attempted to make the subjects as familiar with the procedures and equipment of the experiment as possible. The experiment started over the following 8 weeks.

\section{Procedures}

Before starting resistance training, blood samples are collected from participants in EDTA tubes. This procedure is repeated after weeks of resistance training. The estimations of the laboratory are as follows:

1. Determination of IGF1 form one using a commercial kit and Elisa technique

2. Gene expression: DNA was transcribed to RNA as follows
a. Transcription of DNA to RNA
b. Conversion of primary RNA to mRNA
c. mRNA transport from the nucleus to cytosol translation
d. Translation of mRNA to protein.

First, the transcription generated from DNA is reviewed by the synthesis kit (Roche diagnostic), and then specific primers (according to the manufacturer's instructions) are used for polymerase 
chain reaction (PCR) to amplify the IGF1 gene. Initial denaturation takes 2 min at 94 degrees in a thermocycler, 0.35 cycles of amplification are done, and then a final extension occurs at 78 degrees for $5 \mathrm{~min}$. The products of PCR are separated through electrophoresis and the amplified reverse transcription PCR (RT-PCR) products are cloned and squirted using the Blastx program, by the manufacturer's instructions (Figure 1).

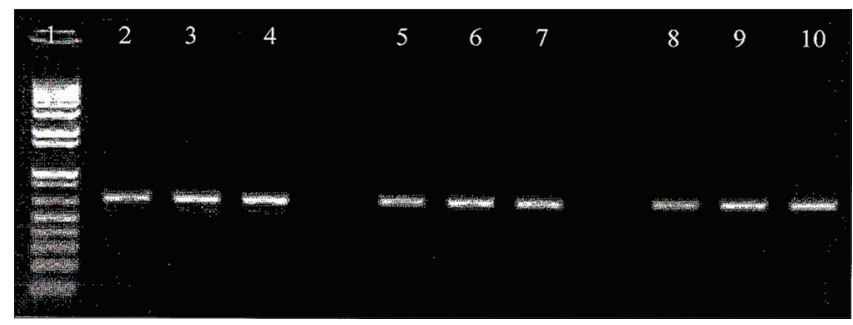

Figure 1: mRNA expression using reverse transcription polymerase chain reaction

\section{The training program}

The program consists of 8 weeks of training that includes specific medicine ball work (Table 2) and free weight training exercises. Initially, the experimental group is presented with accurate lifting techniques. Subjects are required for nonconsecutive training twice a week for $90 \mathrm{~min}$. Every training day consists of a medicine ball ( $3 \mathrm{~kg}$ ) work (3 sets of 8 reps) and free weight resistance work (3 sets of 8 reps). Each training session includes standardized warm-up and cool-down periods; $10 \mathrm{~min}$ of pulse-raising and dynamic/mobilizing flexibility activities. The warm-up exercises are performed in a light circuit to mimic the patterns of movement applied in the program. The cool-down exercises are performed with five minutes of low-level cycling then a static whole-body stretching routine (1 set of $12 \mathrm{~s}$ per muscle group). Resistance training has to be continued in a controlled manner until failure. Each exercise starts with 3 sets of reps, then the resistance increases by $5 \mathrm{~kg}$ after achieving 3-8 reps. Medicine ball exercises are performed explosively, taking into consideration that the medicine ball is released at the end of each movement to raise the sequential acceleration of the chosen movements. Each training log is assigned for each participant, and a qualified fitness instructor is appointed to supervise all training sessions. The training program is designed after the Hat field (ISSA's certified fitness trainer program 2013) in which the muscle training sets are repeated (3 steps/8 reps) to reach hypertrophy, at which time hormones move to the growth process and muscle remodeling. Here comes the essential impact of $\mathrm{GH}$ in adapting to the stress of resistance exercises, considering that highly intensive resistance training (8 repetitions at $75 \%$ of IRM) increases the level of $\mathrm{GH}$. Training includes 3 sets, each exercise of a total high workload followed by a short 1-min exercise the following period. Regarding upper-body speed and strength, medicine ball exercises ( $3 \mathrm{~kg}$ weight) are an excellent method of training. The ball is made of rubber, leather, or stubbing so that it is held securely when thrown. It is worth noting that compensatory acceleration training can be done literally without inertia due to medicine ball training as the stress created on the joints is barless when the ball is released.

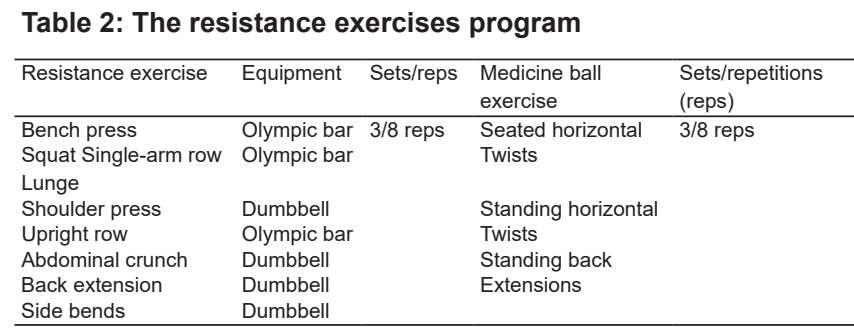

\section{Muscular strength test}

The participant's posture, range of motion, and starting position for selected activities should be considered in the following strength tests: Handgrip strength, arm strength, leg strength, back strength, and abdominal strength.

To measure muscle strength, a dynamometer was used. The determination of IGF1 hormones was carried out using the commercial kit and Elisa process. Gene expression: DNA was transcribed into protein-translated RNA. Those proteins could be hormones and proteins of the structure. Gene expression assessment was conducted in the following steps:

\section{T-DNA isolation}

2. Applying for the training program

3. Muscle strength measurements

4. The IGF1 hormone determination was performed using the commercial kit and Elisa method

5. Gene expression: DNA was transcribed in the form of RNA which was translated into proteins. These proteins could be hormones and structural proteins

The measuring of gene expression was performed in the following steps:

- Isolation of Total RNA from the target blood

- $\quad$ Selection of mRNA from the total RNA

- $\quad$ Conversion of mRNA into C DNA by reserve transcription using oligo DT primers

Enzymatic amplification of C DNA using specific primers by PCR

Quantitation of the C DNA level reflects the level of mRNA that represents gene expression of the target protein. 


\section{Statistical analysis}

SPSS software package is used to describe and analyze data. Description of data reflects as: means \pm standard error $(M \pm S E)$, skewness. The nonparametric Mann-Whitney $U$ test is used to compare the groups. A value of $<0.05$ is considered statistically significant.

\section{Results}

In the previous table, the mean age for experimental group is 20.4 and control group is 21.1, mean BMI in experimental group 21.3 and control group 20.6 and all demographic data show no statistically significant.

In the previous table, the mean IGF (pre resistance training) for experimental group is 82.9 and control group is 77.3 and this data are significantly increased, mean IGF (post resistance training) for experimental group is 131 and control group is 106 , and this data are significantly increased.

In the previous table, the mean Handgrip (pre and post exercises) for experimental group is 41.3 and 46.8, respectively, and control group is 40.9 and 43.4 , respectively; this data is significantly increased. Furthermore, mean Arm strength (pre and post exercises) for experimental group is 22.1 and 26.4, respectively, and control group is 21.7 and 23.8, respectively; this data is significantly increased.

Furthermore, mean Handgrip (pre and post exercises) for experimental group is 41.3 and 46.8 , respectively, and control group is 40.9 and 43.4, respectively; this data is significantly increased. Furthermore, mean Leg strength (pre and post exercises) for experimental group is 73.9 and 78.7, respectively, and control group is 72.6 and 75.3, respectively; this data is significantly increased.

Furthermore, mean Back strength (pre and post exercises) for experimental group is 52.1 and 58.4, respectively, and control group is 52.2 and 54.9 , respectively; this data is significantly increased. Furthermore, mean Abdominal strength (pre and post exercises) for experimental group is 33.7 and 39.4, respectively, and control group are 32.8 and 35.6, respectively; this data is significantly increased.

(Table 3) revealed the individual gene expression of an experimental and control group, Experimental (GR) mRNA show higher gene expression than control group meanly in variable 1 and 9 with 20.2 and 17.2 as shown in Table 3.
Table 3: Individual gene expression of the experimental and control groups

\begin{tabular}{lllllllllll}
\hline Variable & 1 & 2 & 3 & 4 & 5 & 6 & 7 & 8 & 9 & 10 \\
\hline Experimental (GR) mRNA & 20.2 & 12.3 & 9.8 & 10.9 & 7.7 & 11.2 & 9.10 & 6.8 & 17.2 & X
\end{tabular}

$\begin{array}{lllllllllll}\text { Control (gr) mRNA } & 9.1 & 7.3 & 8.1 & 6.7 & 7.4 & 9.6 & 7.5 & 6.3 & 9.5 & 7.0\end{array}$

\section{Discussion}

After 8 weeks of resistance training, IGF1 levels were elevated as illustrated in the (Table 4). The same result is obtained by Grocott et al. [11] and is consistent with Hedelin et al. [12]. Moreover, it was reported by Bloom et al. [13] that $\mathrm{GH}$ has a direct lipolytic influence on adipose tissue, which consequently triggers the release of ketone bodies, glycerol, and free fatty acids (FFA) in turn from metabolic signals. An example of such metabolic signals is endogenous FFA that plays an essential role in the neuroendocrine control of $\mathrm{GH}$ secretion.

Table 4: IGF 1 concentration pre and post programs: Experimental and control groups

\begin{tabular}{|c|c|c|c|c|c|c|}
\hline \multirow[t]{3}{*}{ Variable } & \multicolumn{2}{|c|}{ Experimental } & \multirow[t]{3}{*}{ Sig } & \multicolumn{2}{|l|}{ Control } & \multirow[t]{3}{*}{ Sig } \\
\hline & pre & post & & pre & post & \\
\hline & M SE & M SE & & M SE & M SE & \\
\hline IGF 1 (mall) & $82.9 \pm 8.1$ & $131 \pm 9.1$ & $S$ & $77.3 \pm 6.2$ & $10.6 \pm 7.5$ & $\mathrm{~S}$ \\
\hline
\end{tabular}

A study conducted by Hedelin et al. [12] demonstrated that IGF1is primarily on $\mathrm{GH}$ dependent and affects $\mathrm{GH}$ secretion through a negative feedback system. IGF1 serum is inversely related to body fat percentage. Furthermore, Bloom et al. [13] noted that the concentration of $\mathrm{GH}$ is increased due to incremental exercise. However, the authors expressed the difficulty of explaining the increase in the concentration of $\mathrm{GH}$ during intense training. Thus, it can be concluded that the main function of $\mathrm{GH}$ is to inhibit glucose uptake by peripheral tissues and elevated FFA. As a result, greater stimulation of muscle glycogen synthesis is created by maintaining blood glucose. This process is reinforced by rapid increases in skeletal muscle lipid catabolism and an increase in IGF.

García-López [14] reported an improvement in RNA response due to electrostimulation of muscle cells. That study provided evidence regarding the physiological role played by the IGF1 hormone in skeletal muscle adaptation to exercise and gene expression regulation. In general, muscular strength is the maximal force performed by a muscle or muscle group at a specific velocity. In addition, Bloom et al. [13] illustrated that strength measurements contribute to monitoring improvement during a resistance training program. Accordingly, these programs are adopted by persons of all ages and health states. This finding is displayed in the (Table 5), which shows a significant improvement in back, leg, arm, grip, and abdominal strength after the following resistance training program. 
Table 5: Variable changes pre and post exercises of experimental and control groups

\begin{tabular}{|c|c|c|c|c|c|c|}
\hline \multirow[t]{3}{*}{ Variable } & \multicolumn{2}{|c|}{ Experimental } & \multirow[t]{3}{*}{ Sig } & \multicolumn{2}{|l|}{ Control } & \multirow[t]{3}{*}{ Sig } \\
\hline & Pre & Post & & Pre & Post & \\
\hline & M SE & M SE & & M SE & M SE & \\
\hline Handgrip, $\mathrm{Kg}$ & $41.3 \pm 2.7$ & $46.8 \pm 9.1$ & $S$ & $40.9 \pm 1.8$ & $43.4 \pm 2.3$ & $\mathrm{~s}$ \\
\hline Arm strength, $\mathrm{Kg}$ & $22.1 \pm 1.2$ & $26.4 \pm 1.1$ & $\mathrm{~s}$ & $21.7 \pm 1.5$ & $23.8 \pm 1.4$ & $\mathrm{~s}$ \\
\hline Leg strength, $\mathrm{Kg}$ & $73.9 \pm 2.8$ & $78.7 \pm 4.2$ & $\mathrm{~s}$ & $72.6 \pm 2.6$ & $75.3 \pm 3.7$ & $\mathrm{~s}$ \\
\hline Back strength, kg & $52.1 \pm 3.6$ & $58.4 \pm 4.2$ & $\mathrm{~s}$ & $52.2 \pm 2.9$ & $54.9 \pm 3.4$ & $\mathrm{~s}$ \\
\hline Abdominal strength, $\mathrm{kg}$ & $33.7 \pm 2.7$ & $39.4 \pm 36$ & S & $32.8 \pm 1.8$ & $35.6 \pm 1.9$ & $\mathrm{~S}$ \\
\hline
\end{tabular}

Denegar and Perrin [15] suggested that there is a wide range of strengths at a certain age or gender. Strength differences within an age group may be due to many reasons, for instance, the variation in maturity as every child matures at a different rate. That is why the $\mathrm{X}$-ray measurements of two 12-year-olds may indicate that their biological or maturation age is 10 years old and 15 years old, respectively. This was proven by a study conducted by Hedelin et al. (2000) in which he has noted that a 12-year-old who has not matured rapidly is likely to have less development of nerves, lower secretion of male sex hormones- in males- and smaller muscles.

Another study by Shalaby et al. [16] reported many acquired health benefits gained from resistance training. In addition to improving muscular performance and strength, the effects of resistance training include improved body composition, lower blood pressure, reduction in serum lipids, increased flexibility, and improved cardio-respiratory function. Anabolic secretion is affected by several factors that are reported by Lyu et al. [17]. Such factors include low-mid intensity, resistance training with high volume, high-intensity aerobics in shorter duration, and pre-workout nutrition. In pre-workout nutrition, carbohydrates should be avoided 60 min before the workout, whereas in postworkout nutrition fast-acting carbohydrates should be consumed in a 2:1 carbohydrate-to-protein ratio. The authors also considered sleep patterns such as having plenty of sleep and frequent naps, in addition to supplementation by combining arginine and glutamine. It has been noticed that age influences the secretion of the anabolic hormone, which decreases by $14 \%$ every 10 years after the age of 20 . Another influence on anabolic hormone secretion is credited to gender as males' recorded higher hormonal secretion than females.

A study by Impellizzeri et al. [18] has suggested that the relation between muscle types and muscle performance can be detected from muscle fiber types. Muscle types are divided into fast-twitch fibers and slow-twitch fibers, and both types are influenced by the intensity and type of exercises performed. Furthermore, RNA variability was detected among the participants, in 1-9 players, in terms of gene expression, and one blood sample has been clotted.

Buzi et al. [19] have presented a scheme for muscle regeneration through agents that promote growth and consequently increase the size of both existing and newly generated muscle fibers. Therefore,
IGF1 can take advantage of this to enhance the function of muscles. The authors have also tackled the efficiency of growth-promoting agents such as IGF 1 and anabolic steroids. For successful muscle generation, IGF1 activates myoblast proliferation and subsequent differentiation [20], [21]. GHs can enhance and increase fat utilization, bone, and connective tissue formation, as well as protein synthesis. The release of IGF is spontaneously stimulated by the release of $\mathrm{GH}$ in the bloodstream. Produced mainly in the liver, IGFs then bind to receptor sites in muscle cells where they perform many anabolic impacts [22], [23]. The effects of hormonal responses are not determined not only by the amount of IGFs and GH released in the blood but also by the type of training [24].

In 2006, Mougios [10] pointed out that gene expression is greatly affected by exercise at different stages such as the transcription stage which is considered the most important control point. Mougios [10] added that initiation requires a group of proteins called eukaryotic that are released after resistance training. García-López et al. [14] illustrated that RNA response is enhanced by the electrostimulation of muscle cells. This is demonstrated by the study supporting the physiological role of IGF1 in gene expression regulation and skeletal muscle adaptation to exercise. In addition, a significant increases in handgrip, leg, back, arm, and abdominal strength after resistance training (Table 5). The increased data for the experimental group exceeded that of the control group at the end of the experiment [25], [26].

Other researchers have noted the importance of stem cells in muscle hypertrophy and strength. Shalaby and Fadl, [7], [27] noticed skeletal muscle hypertrophy after resistance training due to increased protein synthesis. The increased secretion of gene expression in muscle fibers due to the high content of DNA, and RNA resulted from stem cells of muscle leads to the emergence of satellite cells which are considered myoblasts associated with skeletal muscle fibers. The so-called satellite cells have a significant impact on muscle strength and growth, particularly after resistance training, as these cells divide and one of the resulted cells provides an additional nucleus for muscle fibers.

Notably, IGF1 has a significant role in the diving process of satellite cells and thus leads to increased IGF1 concentration in muscle fiber after resistance training. Therefore, the presence of satellite cells in addition to the action of IGF1 may lead to skeletal muscle hypertrophy. Mougios and Neuhausen et al. [10], [28] demonstrated the impact of resistance training on gene expression and muscle function. Another study conducted by Gaur et al. [25] referred to the impact of resistance training on muscle performance and structure. It was reported that six maximal contractions of muscle in 3 sets per week can lead to an optimal increase in muscle 
strength without being associated with chronic muscle fatigue. Furthermore, it was reported that performing resistance exercises for 6-8 weeks can increase the strength of the muscle by $30 \%$, and increase muscle mass in an equal percentage. This is called muscle hypertrophy, which is associated with increased mitochondrial enzymes, increased number of myofibrils, in addition, to increase in phosphagen metabolic system and stored glycogen by $60-80 \%$, besides an increase in stored fat by $70-100 \%$, and increase in the efficacy of oxidative metabolic system by $45 \%$ [29].

\section{Conclusion}

The current study investigated the significance of employing a resistance training program in light of the results obtained. The study suggested that the program should be uncomplicated at first with greater variation as progression. Then, the resistance can be maximized through progressive specificity and overload. The different gene expressions obtained after training reflect individual variations in response to resistance exercises. At the end of the program, several significant changes have been reported in muscle strength tests such as anabolic adaptation to muscle tissue, and significant change in IGF1 with satellite cells especially in inducing muscle hypertrophy and strength.

\section{References}

1. Shalaby MN, Hussien S, Abdo Sakoury MM, Atiaa AM, Galila MA. The impact of antioxidants in blood pressure and free radicals of athletes. Indian J Forensic Med Toxicol. 15(2):442030. http://doi.org/10.37506/ijfmt.v15i2.15062.

2. Hussien S, Morad DF, Ibrahim NM, Shalaby MN. The effect of using an exercise-nutrition program on some physiological variables on diabetes patients. Indian J Forensic Med Toxicol. 2021;15(2):4030-9. http://doi.org/10.37506/ijfmt.v15i2.15005.

3. Shalaby MN, Fadl MA. Relative indicators and predicative ability of some biological variables on cardiac neural activity for volleyball players. Syst Rev Pharm. 2020;11(9):834-40.

4. Barton-Davis ER, Shoturma DI, Musaro A, Rosenthal N, Sweeney HL. Viral mediated expression of insulin-like growth factor I blocks the aging-related loss of skeletal muscle function. Proc Natl Acad Sci. 1998;95(26):15603-7.

5. Ganguly K. Overview of the internal physiological system of the human body. In: Application of Biomedical Engineering in Neuroscience. Berlin: Springer; 2019. p. 3-38.

6. Humbel RE. Insulin-like growth factors I and II. Eur J Biochem. 1990;190(3):445-62. http://doi.org/10.1111/j.1432-1033.1990. tb15595.x

PMid:2197088

7. Shalaby MN, Fadl MA. A proposed training program and its effect on muscle strength responses and some physiological variables for volleyball beginners. Syst Rev Pharm. 2020;11(12):515-9.

8. Shalaby M, Sakoury MM, Harthi SM, Alshalawi FM, Alhajji MM, Alshaikh ZH, et al. Vitamin D3 for health and muscle functions of athletes. Syst Rev Pharm. 2020;11(9):851-4

9. Hall JE, Hall ME. Guyton and Hall Textbook of Medical Physiology e-Book. Amsterdam, Netherlands: Elsevier Health Sciences; 2020.

10. Mougios V. Exercise Biochemistry. Champaign, Illinois: Human Kinetics Publishers;, 2019.

11. Grocott MP, Levett DZ, Ward SA. Exercise physiology: Exercise performance at altitude. Curr Opin Physiol. 2019;10:210-8.

12. Hedelin R, Kenttä G, Wiklund U, Bjerle PE, HenrikssonLarsén K. Short-term overtraining: Effects on performance, circulatory responses, and heart rate variability. Med Sci Sports Exerc. 2000;32(8):1480-4. http://doi. org/10.1097/00005768-200008000-00017

PMid: 10949015

13. Bloom SR, Johnson RH, Park DM, Rennie MJ, Sulaiman WR. Differences in the metabolic and hormonal response to exercise between racing cyclists and untrained individuals. J Physiol. 1976;258(1):1-18. $\quad$ http://doi.org/10.1113/jphysiol.1976. sp011403

PMid:940045

14. García-López D, Häkkinen K, Cuevas MJ, Lima E, Kauhanen A Mattila $\mathrm{M}$, et al. Effects of strength and endurance training on antioxidant enzyme gene expression and activity in middle-aged men. Scand J Med Sci Sports. 2007;17(5):595-604. http://doi. org/10.1111/j.1600-0838.2006.00620.x

PMid:17316373

15. Denegar CR, Perrin DH. Effect of transcutaneous electrical nerve stimulation, cold, and a combination treatment on pain, decreased range of motion, and strength loss associated with delayed onset muscle soreness. J Athl Train. 1992;27(3):200-6. PMid:16558162

16. NaderShalaby M, Liu JY, Heshmat H, Shalaby NM, Salah M. The effect of aerobic and anaerobic exercise bouts on CD34+ stem cells and some physiological parameters. Life Sci J. 2012;9(2):1037-43.

17. Lyu $\mathrm{Y}$, Xue L, Zhang F, Koch $\mathrm{H}$, Saba L, Kechirs $\mathrm{K}$, et al Condition-adaptive fused graphical lasso (CFGL): An adaptive procedure for inferring condition-specific gene co-expression network. PLoS Comput Biol. 2018;14(9):e1006436.

18. Impellizzeri FM, Marcora SM, Castagna C, Reilly T, Sassi A laia FM, et al. Physiological and performance effects of generic versus specific aerobic training in soccer players. Int J Sports Med. 2006;27(6):483-92. http://doi.org/10.1055/s-2005-865839 PMid: 16767613

19. Buzi F, Mella P, Pilotta A, Prandi E, Lanfranchi F, Carapella T. Growth hormone receptor polymorphisms. Congenit Endocrinopathies. 2007;11:28-35.

20. Williams RH. Textbook of Endocrinology. Acad Med. 1962;37(5):527.

21. Morikawa A, Inamizu T, Han $Y$, Nagata M. Effects of exercise training on superoxide dismutase gene expression in human lymphocytes. Int J Sport Health Sci. 2004;2:187-94.

22. Lis K. Insulin-like growth factor 1 (IGF-1) and growth hormone $(\mathrm{hGH})$ as the markers of osteoarthritis. Chir Narzadow Ruchu Ortop Pol. 2008;73(1):49-52.

PMid:18683531

23. Kostek MC, Delmonico MJ, Reichel JB, Roth SM, Douglass L, Ferrell RE, et al. Muscle strength response to strength training is influenced by insulin-like growth factor 1 genotype in older adults. J Appl Physiol. 2005;98(6):2147-54. http://doi. org/10.1152/japplphysiol.00817.2004

PMid: 15894537 
24. Kim B, Leventhal PS, White MF, Feldman EL. Differential regulation of insulin receptor substrate-2 and mitogen-activated protein kinase tyrosine phosphorylation by phosphatidylinositol 3-kinase inhibitors in SH-SY5Y human neuroblastoma cells. Endocrinology. 1998;139(12):4881-9. http://doi.org/10.1210/endo.139.12.6348 PMid:9832424

25. Gaur S, Schwartz Y, Tai LR, Frick GP, Goodman HM. Insulin produces a growth hormone-like increase in intracellular free calcium concentration in okadaic acid-treated adipocytes. Endocrinology. 1998;139(12):4953-61. http://doi.org/10.1210/ endo.139.12.6387

PMid:9832433

26. Jain S, Golde DW, Bailey R, Geffner ME. Insulin-like growth factor-I resistance. Endocr Rev. 1998;19(5):625-46. http://doi. org/10.1210/edrv.19.5.0348

PMid:9793761
27. Shalaby MN, Liu JY, Saad M, Elaraby H. Impacts of different exercise intensities on hematopoietic stem cells and certain physiological parameters on handball players and non-athletes. Life Sci J. 2012;9(3):2100-5

28. Neuhausen SL, Slattery ML, Garner CP, Ding YC, Hoffman M, Brothman AR. Prostate cancer risk and IRS1, IRS2, IGF1, and INS polymorphisms: Strong association of IRS1 G972R variant and cancer risk. Prostate. 2005;64(2):168-74. http://doi. org/10.1002/pros.20216

PMid:15678496

29. Alemdaroğlu U. The relationship between muscle strength, anaerobic performance, agility, sprint ability and vertical jump performance in professional basketball players. J Hum Kinet. 2012;31(1):149-58.

PMid:23486566 